\title{
SELF-INCOMPATIBILITY SYSTEMS IN ANGIOSPERMS II. IBERIS AMARA
}

\author{
A. J. BATEMAN \\ John Innes Horticultural Institution \\ (now at Christie Hospital and Holt Radium Institute, Manchester)
}

\section{INTRODUCTION}

Received 14.viii.53

Self-Incompatibility is known to be widespread in the Cruciferae and to include the economically important genus Brassica. No one has yet succeeded, however, in obtaining a coherent picture of the incompatibility system involved. In an earlier paper (1952) I have drawn attention to the need for a critical survey of angiosperm families to discover whether any hitherto undisclosed incompatibility systems were operating. It appeared therefore that the Gruciferae would repay closer study.

Three species have already been studied in some detail ; Cardamine pratensis (Correns, I913), Brassica oleracea (Kakizaki, 1930) and Capsella grandiflora (Riley, I 936) and quite different mechanisms were invoked by the respective authors to explain the results in each species. Experience in the Solanaceae (Nicotiana, Petunia, Solanum), Scrophulariaceae (Veronica, Antirrhinum, Nemesia), Plumbaginaceae (Limonium, Armeria, Acantholimon, see Baker, 1948) and now Compositae (Parthenium, Crepis, Cosmos) indicates a uniformity in the self-incompatibility system operating in a given family. It appeared possible and desirable therefore to derive an incompatibility system which would fit all the data so far obtained in the Cruciferae.

In surveying the family for suitable experimental material I chose Iberis amara. Ironically, Darwin in "Cross and Self-fertilisation of Plants" describes it, together with $I$. umbellata, cabbage and radish, as self-fertile. I. amara is an annual which can be over-wintered if sown in autumn, but $I$ have been unable to prevent it from dying after completion of flowering, so that it has not been possible to test the progenies against their parents.

(a) Stigma flushing.-This disadvantage is more than offset by the hundreds of flowers per plant and, especially, the flushing of stigma and style with purple anthocyanin following fertilisation, which seems to be a feature of the whole genus. This flushing is followed by the drying up of the stigma as it becomes un-receptive. An unpollinated or incompatibly pollinated stigma remains fresh, green and receptive indefinitely. Compatible pollen tubes grow down the style in about twelve hours. The flushing of the stigma has begun 24 hours after pollination and has developed the maximum intensity within $4^{8}$ hours.

Incompatible pollen barely penetrates the stigmatic surface. This 
early inhibition of the pollen has been observed in Capsella (Riley, I932), Radish (Lewis, unpub.), Brassica pekinensis (Stout, I93I), and $B$. oleracea (Sears, I937) and would therefore appear to be typical of Gruciferae. (A further indication that Crucifers have a common system.) The flush following compatible pollination enables one to carry out extensive series of pollinations duly determined by the reactions produced by pollinations of two days before. Also all unexpected or incomplete reactions can be repeated at once. Normally, five or six flowers are pollinated with any one cross, never less than three. It is necessary to carry out the pollination programme speedily because, as the plants become senescent, the flushing becomes tardier and weaker.

As might be expected, there is a strong correlation between the flushing of the stigma and seed setting. It is not complete however. Sometimes flushing is followed by failure to produce ripe seed. The first flowers produced on a plant are frequently incapable of forming ripe fruits. Sometimes a negative reaction is followed by partial setting, usually a half-fruit (each of the two carpels in Iberis contains one seed). This could be due to the slow growth of an only partially inhibited pollen tube. Since the stigma reaction is nearer to fertilisation than fruit development it is likely to be the more reliable of the two as an indication of compatibility.

It is worth noting that crosses between Iberis amara and other species such as lagascana and sempervirens produced the flushing just as readily as intraspecific pollinations (without producing any fruits), but no flushing followed crosses with more distant relatives such as species of Lepidium, Sisymbrium, Erysimum or Arabis. No observations were made on the distance travelled by the pollen tubes in these latter crosses. The sterility of all the species crosses confirms that the flushing of the stigma must be induced by a stage closely following fertilisation, if not by fertilisation itself.

Investigations into the mechanism were made in two series using material from different sources. The first series was exploratory. The second was more intensive, being based on the knowledge acquired from the first.

\section{FIRST SERIES}

The parent plants were grown in the spring of 1950 from seed supplied by the Helsinki Botanic Garden. Among the six plants (designated A-F) only the pollinations between $\mathrm{A}$ and the other five, in either direction, were compatible. Thus the six plants appeared to belong to two compatibility groups. Some seed was raised by selfing in the bud and selfing after cutting off the stigma, though neither produced an appreciable increase in seed setting.

Difficulty was encountered in that some families contained selffertile plants, which were reciprocally cross-fertile with all other plants. The presence of self-fertile individuals did not reduce the 
number of groups in a family so it was presumed that the self-fertility gene was not at the S-locus. There were also some male-sterile plants which could not be tested reciprocally. Sometimes, when self-fertility and male-sterility occurred in the same family, a male-sterile plant would be cross-fertile with all hermaphrodite sibs. In such cases it was presumed that these plants had the self-fertility genes masked by their male-sterility.

The original intention had been to make all possible pollinations within each family. But since, after making all pollinations, family 2 failed to disclose more than two groups, the procedure was modified as follows. One plant from each family was tested as female against all the rest. In general this revealed two groups, compatible and incompatible. A second plant from the same group as the first and

KeY to FamiLIES

\begin{tabular}{|c|c|c|c|c|c|}
\hline \multicolumn{3}{|c|}{ First sowing } & \multicolumn{3}{|c|}{ Second sowing } \\
\hline $\begin{array}{c}\text { Family } \\
\text { no. }\end{array}$ & Cross & $\begin{array}{l}\text { No. of } \\
\text { plants }\end{array}$ & $\begin{array}{c}\text { Family } \\
\text { no. }\end{array}$ & Cross & $\begin{array}{l}\text { No. of } \\
\text { plants }\end{array}$ \\
\hline I & $A \times B$ & ro & 8 & $\begin{array}{c}\text { As (after decapita- } \\
\text { tion of stigma) }\end{array}$ & I \\
\hline 2 & recip. & 17 & 9 & $\mathrm{~B} \times \mathrm{D}(?)$ & 5 \\
\hline 3 & $A \times C$ & 14 & ro & Bs (bud) & 5 \\
\hline 4 & recip. & 14 & II & Bs (decap.) & o \\
\hline 5 & $A \times D$ & 6 & 12 & Es (bud) & 6 \\
\hline 6 & recip. & 13 & I3 & Es (decap.) & 6 \\
\hline 7 & $\mathrm{E} \times \mathrm{A}$ & 12 & 2 & $\mathrm{~B} \times \mathrm{A}$ (resowing) & I I \\
\hline
\end{tabular}

two from the second group were tested again in the same way. In general this still only revealed two groups and it is doubtful in that case whether further intra-family pollinations would have yielded any more information. In the inter-family pollinations only one plant from each group was used and then not reciprocally (because there had previously been very few reciprocal differences : 2 out of 92 pairs of pollinations). Experience from the second series shows that it would have been better to have used three plants from each group in an attempt to include the two genotypes of each group in the pollinations, and to have tested all reciprocally.

(a) General.-After excluding the self-fertile plants the families generally contained only two mating groups. (The exceptions will be considered later.) With gametophytic determination of pollen (as in Nicotiana) this could only mean that the parents had one S-allele in common; and in consequence reciprocal matings would yield unlike families :

$$
\begin{aligned}
& \mathrm{Sr}_{2} \mathrm{~S}_{2} \times \mathrm{S}_{2} \mathrm{~S}_{3} \rightarrow \mathrm{Sr} \mathrm{S}_{3}+\mathrm{S}_{2} \mathrm{~S}_{3} \\
& \mathrm{~S}_{2} \mathrm{~S}_{3} \times \mathrm{Sr} \mathrm{S2} \rightarrow \mathrm{Sr} \mathrm{S} 3+\mathrm{Sr} \mathrm{S}_{2} .
\end{aligned}
$$

In Iberis, however, reciprocal matings yielded the same two groups. 


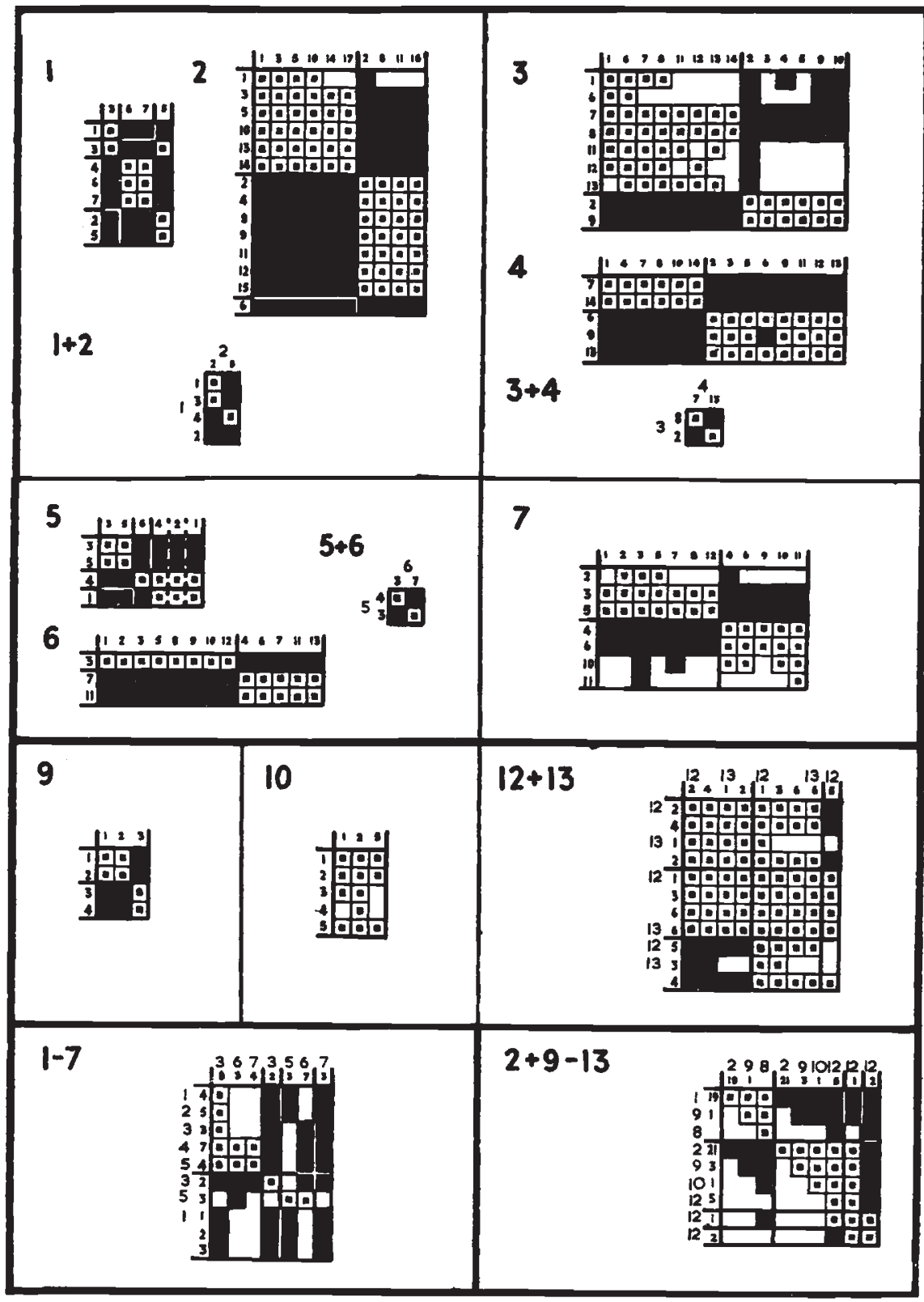

Fic. 1.-The results of all intra- and inter-family pollinations of the first series, excluding self-fertiles. Rows represent plants tested as females, columns plants tested as males. Plants have been grouped according to their behaviour. Symbols :

compatible pollination.

incompatible pollination.

Blank : pollination not made.

In family 5 it was not possible to classify plant 2, so it is separated from the two groups to which it might belong by broken lines. 
The most critical evidence is from families 12 and 13 combined (E selfed). Of 12 plants $I$ was self-fertile. The remaining I I fell into three groups, so the plant $\mathrm{E}$ must have been heterozygous. One of the three groups was reciprocally incompatible with both the others. These were reciprocally cross-compatible (see fig. I). The constitution of parent $\mathrm{E}$ is given as $\mathbf{S}_{3} \mathbf{S}_{7}$. The three groups would then be

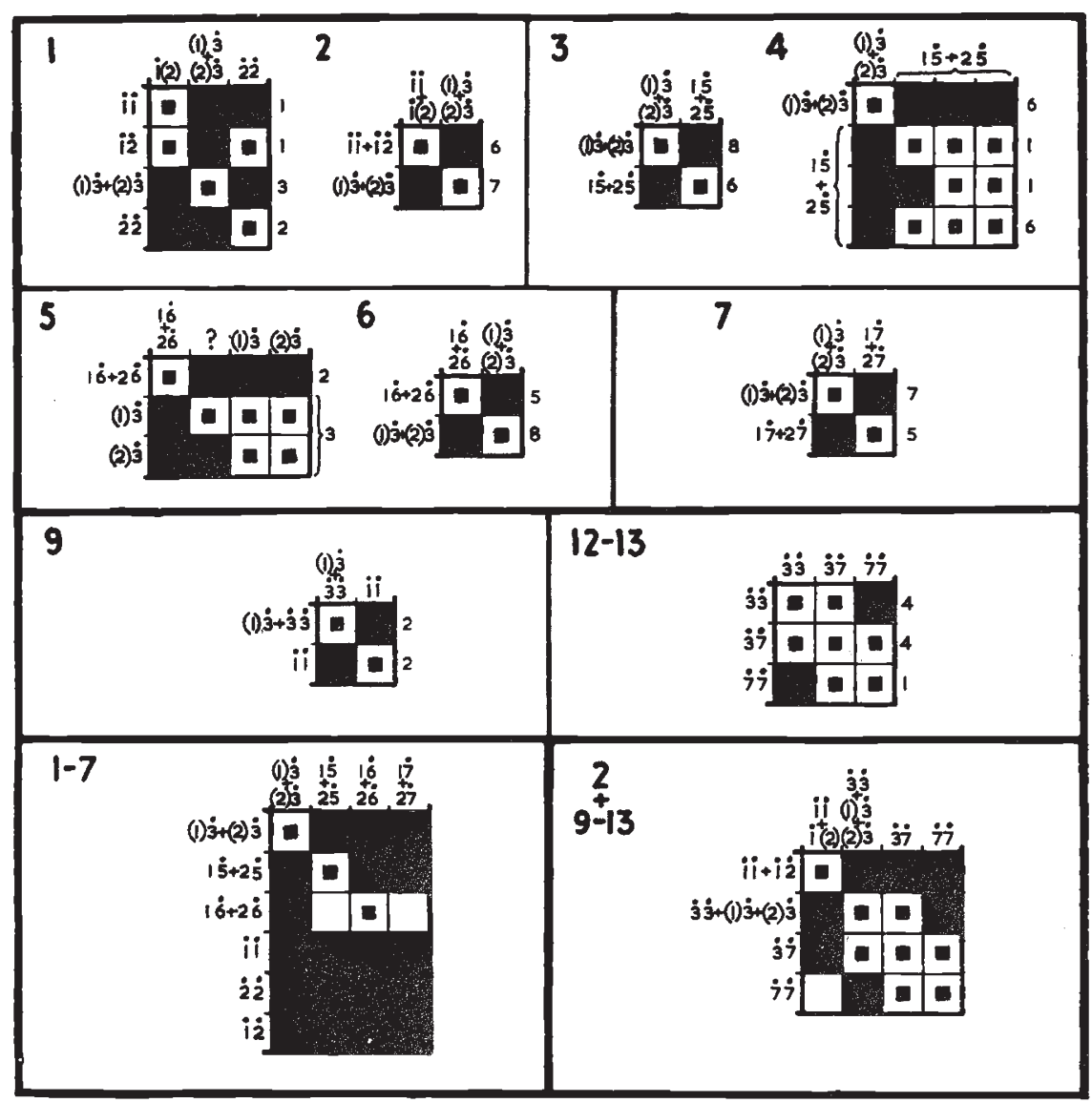

FrG. 2.- Interpretation of the results given in fig. 1. Each mating group is now represented by a single row or column with the genotype and phenotype (style and pollen) and frequency (to right of rows) indicated.

$\dot{i}$ indicates an active allele.

(x) an inactive (recessive) allele.

I no evidence.

$S_{3} S_{3}, S_{7} S_{7}$ and $S_{3} S_{7}$ and all pollen of $S_{3} S_{7}$ was rejected by both $S_{3} S_{3}$ and $S_{7} S_{7}$. The reaction of the pollen of $S_{3} S_{7}$ must be sporophytically determined with independent action of both alleles.

The two groups in each pair of reciprocal families could be due to the homozygosity of common parent A. The evidence of family I, apparently contaminated by seed of A selfed, indicates however, that A was heterozygous and that the two mating groups of the other 
families hide four genotypes whose identity is hidden by dominance. Inter-family pollinations revealed that there was one group common to all the families, except 8 , which (being A selfed) differed from all the rest in not being descended from one of the inter-sterile parent plants B-E. Evidently this group had in common the S-allele which produced the cross-incompatibility between the parents B-E.

In general the results are consistent with the following parental genotypes :-

$$
\text { A, SI S2 ; B, SI S3 ; C, S3 S5 ; D, S3 S6 ; and E, S3 S7. }
$$

In all further discussion, for the sake of clarity, the $\mathbf{S}$ symbols will be omitted and the genotypes will be represented by the numbers alone in heavy type. The activity of an allele is denoted as follows. Where proven to be active the number of the allele has a dot over, $\dot{3}$ : when proven to be inactive (recessive) it is in parenthesis, $(3)$; otherwise the number is unqualified, 3.

The evidence both of genotype and of activity of individual alleles is not as unambiguous in this series as in the second series and I do not propose to discuss it further. A full treatment of the method of deduction will be given for the second series.

The interpretation of the results of fig. I in terms of S-alleles is shown in fig. 2.

(b) Activity of S-alleles. - The data can be summarised as follows :

We have encountered 16 genotypes and have discovered the following information about their constituent alleles. One genotype has been shown to behave differently in pollen and style : the phenotype of parent $A$ is $\dot{i} . \dot{z}$ in style and $\dot{i} .(2)$ in pollen. Seven other genotypes (four of them homozygous) are known to behave alike in

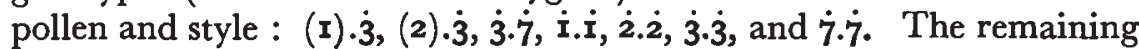
8 genotypes have not been fully tested and it is not known whether the style and pollen reactions are the same: $3.5,3.6,1.5,2 . \dot{5}$, I. $\dot{6}, \mathbf{2 . \dot { 6 }}, \mathbf{I} . \dot{7}$ and 2.j. We know that at least one of the alleles I and 2 is recessive in the pollen to each of 5,6 and 7 .

If we assume that alleles which are independent of each other will bear similar dominance relations to further alleles (which by analogy with step-allelomorphs is to be expected and might be used as a working hypothesis) we can place the alleles in a descending order of dominance.

Then in the style $\quad 3=7 \simeq 5$ and $6>1=2$. and in the pollen $3=7 \bumpeq 5$ and $6>1>2$.

(c) Conclusions.-The experiment has established the following facts. Incompatibility in Iberis amara involves sporophytic control of the pollen as well as the style. There are several alleles, 5 plants from a botanic garden population (probably very small) sharing 6 alleles between them (one of the original 6 plants was not represented in the progenies). Pairs of alleles can show independence or dominance, 
in either pollen or style. The dominance relations of a series of alleles show a strong but not complete correlation between pollen and style. This lack of correlation is reflected in 2 out of 92 pairs of reciprocal pollinations being discordant.

Self-fertility seems to be fairly frequent, the breakdown of incompatibility appearing to occur equally on the male and female sides for pollinations between self-fertile and self-sterile plants are reciprocally compatible. In this material the self-fertility is not due to a change at the S-locus.

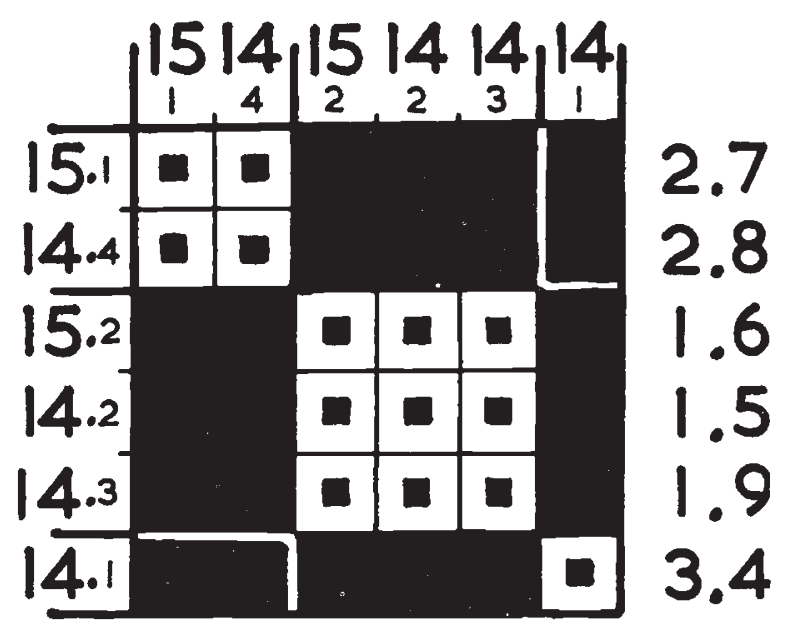

Fig. 3.-Compatibility relationships of the parent plants of the second series. There are three cross-compatible classes and no reciprocal differences. Proposed genotypes entered at right of rows.

The reliability of the technique can be judged by the fact that out of $55^{2}$ different cross-pollinations only one $\left(4^{9} \times 4^{6}\right)$ was inexplicable.

\section{SECOND SERIES}

A second series of crosses was made in $195 \mathrm{I}$, to test whether the conclusions from the first series applied in unrelated material, and to obtain more extensive information on the dominance and other inter-relations of a sample of S-alleles.

The parental material was obtained from Poznan Botanic Garden in two seed packets : one labelled I. amara, sown as family 14 , the other I. amara alba odorata, sown as family I5. The two packets produced very similar plants which showed as much cross-incompatibility between packets as within packets, so they probably came from the same population. Their compatibility relationships are shown in fig. 3 .

Assuming sporophytic control, plants 15.2 , 14.2, and 14.3 must have a common allele, say $S_{1} *$ and plants I5. and 14.4 must also

* The numbering of the alleles in the second series is quite independent of that of the first series. There was no cross testing. 
have had a common allele, say S2. The maximum number of alleles shared among the six plants is therefore nine. The other seven alleles have been numbered $S_{3}$ to $S_{9}$, the final numbers being allocated in

TABLE I

Origin and constitution of families $16-35$

\begin{tabular}{|c|c|c|c|c|c|}
\hline $\begin{array}{l}\text { Family } \\
\text { number }\end{array}$ & $\begin{array}{l}\text { Number } \\
\text { of plants }\end{array}$ & $\begin{array}{c}\text { Parent } \\
\text { numbers }\end{array}$ & $\begin{array}{c}\text { Parent } \\
\text { genotypes }\end{array}$ & $\begin{array}{l}\text { Genotypes expected } \\
\text { in progeny }\end{array}$ & $\begin{array}{c}\text { Proportion } \\
\text { of self-fertiles }\end{array}$ \\
\hline $\begin{array}{l}16 \\
17\end{array}$ & $\begin{array}{l}10 \\
10\end{array}$ & $\begin{array}{l}14.1 \times 14.2 \\
\text { recip. }\end{array}$ & 3.4 and $x .5$ & $1.3: 1.4: 3.5: 4.5$ & $0 / 20$ \\
\hline 18 & 8 & $14.1 \times 14.3$ & 3.4 and $x .9$ & $x .3: 1.4: 3.9: 4.9$ & $4 / 8$ \\
\hline $\begin{array}{l}19 \\
20\end{array}$ & $\begin{array}{l}7 \\
8\end{array}$ & $\left.\begin{array}{l}\mathrm{I} 4.1 \times \mathrm{I} 4.4 \\
\text { recip. }\end{array}\right\}$ & 3.4 and 2.8 & $2.3: 2.4: 3.8: 4.8$ & $4 / 15$ \\
\hline $\begin{array}{l}21 \\
22\end{array}$ & $\begin{array}{l}10 \\
10\end{array}$ & $\left.\begin{array}{l}14.1 \times 15.1 \\
\text { recip. }\end{array}\right\}$ & 3.4 and 2.7 & $2.3: 2.4: 3.7: 4.7$ & $0 / 20$ \\
\hline $\begin{array}{l}23 \\
24\end{array}$ & $\begin{array}{r}8 \\
10\end{array}$ & $\begin{array}{l}14.1 \times 15.2 \\
\text { recip. }\end{array}$ & 3.4 and $x .6$ & $1.3: 1.4: 3.6: 4.6$ & $0 / 18$ \\
\hline 25 & 12 & $14.2 \times 14.4$ & 1.5 and 2.8 & $x .2: 1.8: 2.5: 5.8$ & $5 / 12$ \\
\hline $\begin{array}{l}26 \\
27\end{array}$ & $\begin{array}{l}10 \\
10\end{array}$ & $\left.\begin{array}{l}14.2 \times 15.1 \\
\text { recip. }\end{array}\right\}$ & 1.5 and 2.7 & $1.2: 1.7: 2.5: 5.7$ & $0 / 20$ \\
\hline $\begin{array}{l}28 \\
29\end{array}$ & $\begin{array}{l}9 \\
7\end{array}$ & $\left.\begin{array}{l}14.3 \times 14.4 \\
\text { recip. }\end{array}\right\}$ & 1.9 and 2.8 & $1.2: 1.8: 2.9: 8.9$ & $2 / 16$ \\
\hline $\begin{array}{l}30 \\
31\end{array}$ & $\begin{array}{l}5 \\
2\end{array}$ & $\left.\begin{array}{l}14.3 \times 15.1 \\
\text { recip. }\end{array}\right\}$ & 1.9 and 2.7 & $1.2: 1.7: 2.9: 7.9$ & $1 / 7$ \\
\hline $\begin{array}{l}32 \\
33\end{array}$ & $\begin{array}{l}10 \\
10\end{array}$ & $\left.\begin{array}{l}14.4 \times 15.2 \\
\text { recip. }\end{array}\right\}$ & 2.8 and 1.6 & $1.2: 1.8: 2.6: 6.8$ & $6 / 19 *$ \\
\hline $\begin{array}{l}34 \\
35\end{array}$ & $\begin{array}{r}10 \\
6\end{array}$ & $\begin{array}{l}15.1 \times 15.2 \\
\text { recip. }\end{array}$ & 2.7 and $x .6$ & $1.2: x .7: 2.6: 6.7$ & $0 / 15 \dagger$ \\
\hline
\end{tabular}

* The 2oth plant was feeble, male-sterile, and was not tested.

† One plant appeared to be male-sterile and "self-fertile" (see text).

accordance with their position in the dominance series as indicated by the experiment.

We can predict the genotypes to be found in all the families produced by intercrossing the parent plants. These are shown in table I together with the family numbers and the number of plants per family. The proportions of self-fertile plants are also shown. 
Evidence presented later will indicate that these self-fertile plants (in contrast with those of the first series) were so by virtue of their $\mathbf{S}$ constitution. We can in any case be sure that none of the genotypes present in entirely self-sterile families are self-fertile and thus by a process of elimination can arrive at those few genotypes which might be self-fertile.

We can thus classify all genotypes according to their self-sterility and according to the families in which they will be expected.

TABLE 2

Classification of genotypes according to the families in which they are expected

\begin{tabular}{|c|c|c|c|}
\hline Genotype & Family & Genotype & Family \\
\hline \multicolumn{4}{|c|}{ Found in wholly self-sterile families : i.e. self-sterile } \\
\hline $\begin{array}{l}1.2 \\
1.3 \\
1.4 \\
1.5 \\
1.6 \\
1.7 \\
1.9 \\
2.3 \\
2.4 \\
2.5 \\
2.6\end{array}$ & 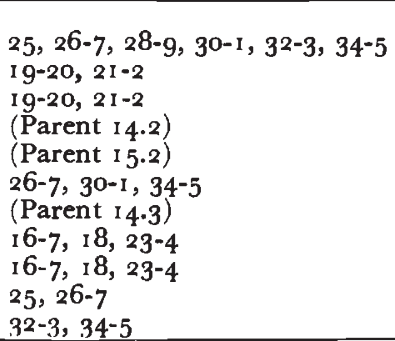 & $\begin{array}{l}2.7 \\
2.8 \\
3.4 \\
3.5 \\
3.6 \\
3.7 \\
4.5 \\
4.6 \\
4.7 \\
5.7 \\
6.7\end{array}$ & $\begin{array}{c}\text { (Parent 15.1) } \\
\text { (Parent 14.4) } \\
\text { (Parent I } 4 \cdot 1 \text { ) } \\
\text { 16-7 } \\
23-4 \\
21-2 \\
16-7 \\
23-4 \\
21-2 \\
26-7 \\
34-5 \\
\end{array}$ \\
\hline \multicolumn{4}{|c|}{ Found only in partially self-fertile families : i.e. possibly self-fertile } \\
\hline $\begin{array}{l}1.8 \\
2.9 \\
3.8 \\
3.9 \\
4.8\end{array}$ & $\begin{array}{l}25,28-9,3^{2-3} \\
28-9,30-1 \\
19-20 \\
18 \\
19-20\end{array}$ & $\begin{array}{l}4.9 \\
5.8 \\
6.8 \\
7.9 \\
8.9\end{array}$ & $\begin{array}{l}18 \\
25 \\
32-3 \\
30-x \\
28-9\end{array}$ \\
\hline
\end{tabular}

It must be remembered that nine is only the maximum possible number of alleles. It is quite likely that the actual number was less, and that different numbers cited above and in table I refer to identical alleles.

(a) Intra-family tests.--Each family consisted of ten plants when possible. The method of making test pollinations was slightly modified from the first series since if four genotypes are expected in a family one must try as far as possible to recognise all four of them. The more rough and ready methods used in the first series had not fully tested or recognised all genotypes. After putting self-fertile plants to one side one plant of the remainder from one of each pair of reciprocal families was tested as $q$ against its sibs. As a rule some were compatible, making a second class. When no compatibility was disclosed (e.g. family 25) two further plants were tested. One plant in any new class was at once tested as seed parent against the remainder. This usually revealed at least one and usually two further classes which were again tested as 9 ?

The next step was to check that the reciprocal had the same four classes by testing against the four test plants of the first family. Agreement was the rule. In family 24 only two classes had been found and 
a third turned up in the reciprocal 23. This in its turn when used as a tester on 24 revealed the fourth class. The four final classes behaved as expected. Details of these intra-family pollinations are shown in fig. $4 \cdot^{*}$

It will be noticed that crosses between identical S-genotypes may be compatible and half-compatible (21-2, 26-7), or incompatible and half-compatible $(26-7,28-9)$. This is not surprising in view of the delicate balance in strength of reaction needed to produce halfcompatibility. Slight variations in modifiers could easily swing it over from full setting to no setting.

In only two pairs of reciprocal families was there any discordance. Family $1 \dot{6}$ and the reciprocal 17 each had four classes but two of those in 17 were represented by single plants neither of which corresponded to one of the four in 16 . The other two classes were represented in both. One plant from each group in 16 had already been entered for the inter-family crosses and the aberrant plants in 17 were not tested further. However, the four test plants from 16 all behaved appropriately so we can assume that the anomalous plants in 17 were contamination of some kind.

The only other family for which it was necessary to invoke contamination was $34-5$. On first examination there appeared to be four mating groups between them, two comprising single plants. One of these, 34.3 , was more or less sterile with all other groups when tested as $\hat{\alpha}$, but compatible with all as 9 . Closer examination showed that though the anthers were of normal size they were empty of pollen. Its behaviour could be explained as that of a self-fertile but male sterile plant (a constitution frequently met with in the first series). Later tests showed $34 . \mathrm{I}$ to be 1.2 with both alleles active. Then 34.7 must be 6.7, with 1.7 and 2.6 as the missing genotypes, both of which are already known to be incompatible with $\mathbf{1 . 2}$ (34.I). Therefore 34.2 does not belong to any one of the four expected groups and is probably a stray seedling. On the other hand 1.7 and 2.6 might well be compatible with 6.7 , in which case from the pollinations shown in fig. 4 they would be classified with 34.1 giving an expected ratio of $3: 1$; the actual ratio is $10: 4$.

The following families had four self-sterile classes (exclusive of presumed contaminants): I6-7, 2I-2, 23-4 and 26-7. These contained no self-fertile plants.

Of the remainder, the following had three self-sterile and one self-fertile class : I9-20, 28-9, 30-I and 32-3. This in itself is a strong indication that the self-fertility (except in 34.3 ?) was due to a particular S-allele constitution.

* In addition to the two types of pollination represented in figure 1 , there is a third in which the square is half blacked out. This has no connexion with the intensity of the stigma coloration which is quite variable but characteristic of the seed parent. It means that only a proportion of the pollinated stigmata flushed. These results were repeatable. They must be due to weak compatibility. In the wild, with open pollination, such weak compatibility would be effective incompatibility. 
Confirmation of this is given by the fact that in a family produced by crossing unrelated plants (though not in one produced by a compatible cross between plants with a common allele) each incompatibility class out of the four will be compatible with at least one
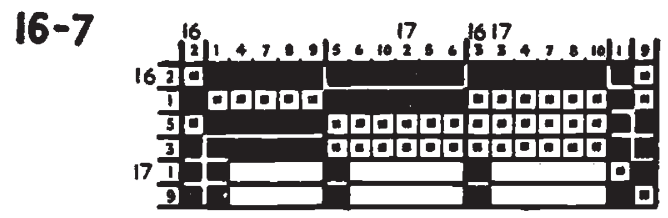

18

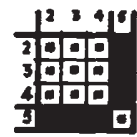

$19-20$

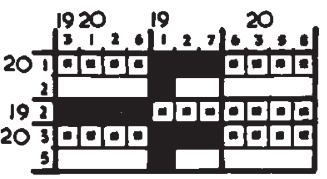

$21-2$

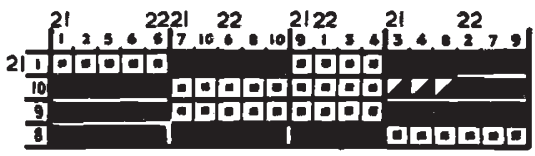

23-4
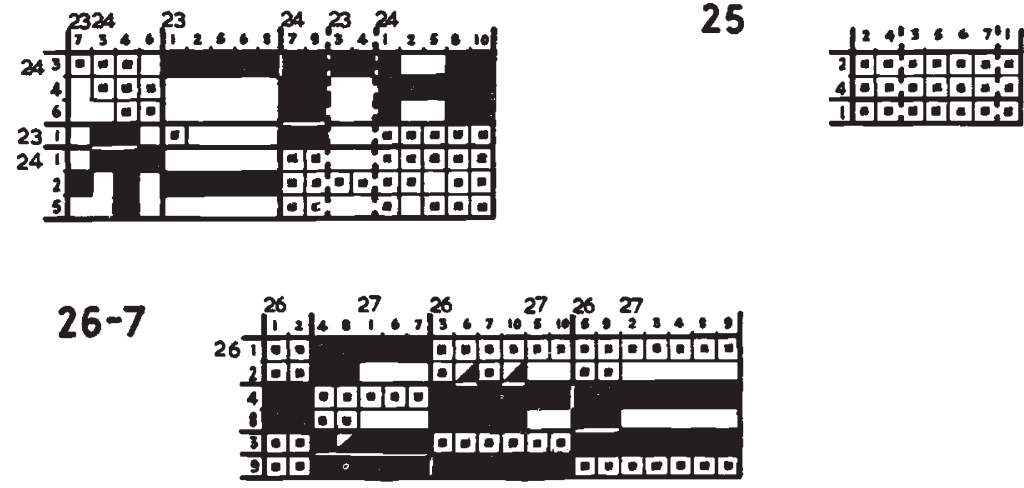

28-9

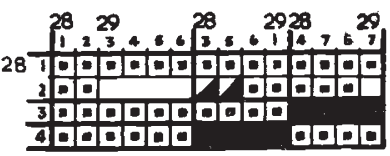

$30-1$

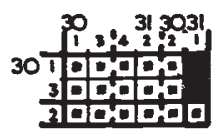

$32-3$
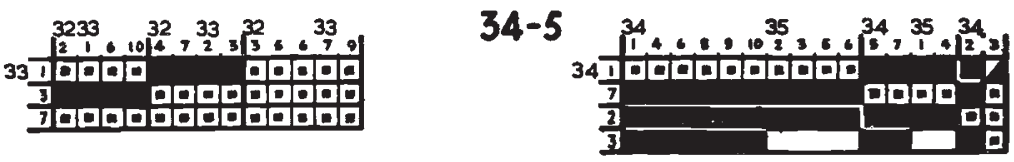

FIG. 4.-Second series. The results of all intra-family pollinations, excluding self-fertiles. Plants have been grouped according to their behaviour. In addition to the symbols of fig. I we have :

$$
\square \text { weakly incompatible. }
$$

other, the complementary one with no common allele. Reference to fig. 4 shows that in families 19-20, 28-9 and 32-3, the pollen of one of the self-sterile classes was incompatible with all the self-sterile plants. Similarly in families $28-9,30-1$ and $32-3$ the style of one of 
the self-sterile classes was incompatible with all the other self-sterile plants. The complementary genotype must have been the self-fertile class.

The following farnilies had less than four classes revealed.

Family I8 had only eight plants and was without a reciprocal. Four plants were self-fertile. The remaining four fell into two classes but one of the expected classes, 1.3, which was known to be self-sterile, was missing from this family. Thus instead of an expected four equal classes we had $3: 1: 0$ (self-sterile) $: 4$ (self-fertile), not an unlikely ratio in a small family.

Family 25 was again without a reciprocal but contained twelve plants of which five were self-fertile. The remaining seven appeared to comprise one class since they were all incompatible with each other. However, just in case two genotypes were present three plants were entered for the inter-family tests. These showed them to comprise two classes, the third self-sterile class being missing. Instead of an expected ratio of $2:$ I : I (two of the classes not being separable) the actual frequencies were $7: 0: 5$ (self-fertile).

Family $34-5$ has already been considered.

The cross-relationships of the classes within a family can give only limited information about the gene actions and give no clue to the identity of the different alleles. Their main value is in the detection of the classes. For further understanding we need inter-family pollinations. (Backcrossing to the parents would be equally informative but is impossible in this annual species.)

(b) Inter-family tests.-One plant was selected from each self-sterile class in a reciprocal pair of families (more than one when a class was suspected of containing more than one genotype) and each was tested against all the other families-thirty-eight plants in all were used. Of those families containing four classes, in 23-4 and 30-I one of the self-sterile classes was disclosed too late to be included in the tests.

The first nine test plants were crossed as female to every other one. As will be expected from table 2, many genotypes were represented several times. In order to save superfluous work test plants behaving alike and coming from families with a common genotype were reduced to one representative. Unfortunately this sometimes resulted in discarding plants with similar phenotypes but different genotypes and consequently other genotypes remiained over represented. Altogether sixteen original test plants were eliminated half-way through, leaving twenty-two. The number of pollinations required was thus reduced from $3^{2}$ (1444) to $22^{2}(484)$. The behaviour of the thirtyeight test plants when pollinated on to the first nine was found to fall into a limited number of patterns. One of these can be excluded : the partially male-sterile $34 \cdot 3$. The remaining thirty-seven plants show only 12 behaviour patterns, some very common, some unique. They are summarised in fig. 5. The patterns are numbered (i) to (xii) and below each are listed the test plants showing that pattern.

It will be seen that the incompatibilities shown by some plants 
are the sum of those shown by others. Thus (iv) has the incompatibilities of (i) and (ii), (v) those of (i) and (iii) and (vi) those of (ii) and (iii). This can only mean that groups (i), (ii) and (iii) each have an active incompatibility allele and that groups (iv), (v) and (vi) have the same alleles active in pairs. If we examine the families represented in group ( $v$ ) and compare them with the data of table 2 we will see that all these families have one common genotype, r.2, in which both alleles must be active in the pollen. For the same reasons group (iv) must be of constitution 2.3 or 2.4 and group (vi) 1.3 or 1.4. It will be noted that, formally, one cannot distinguish between

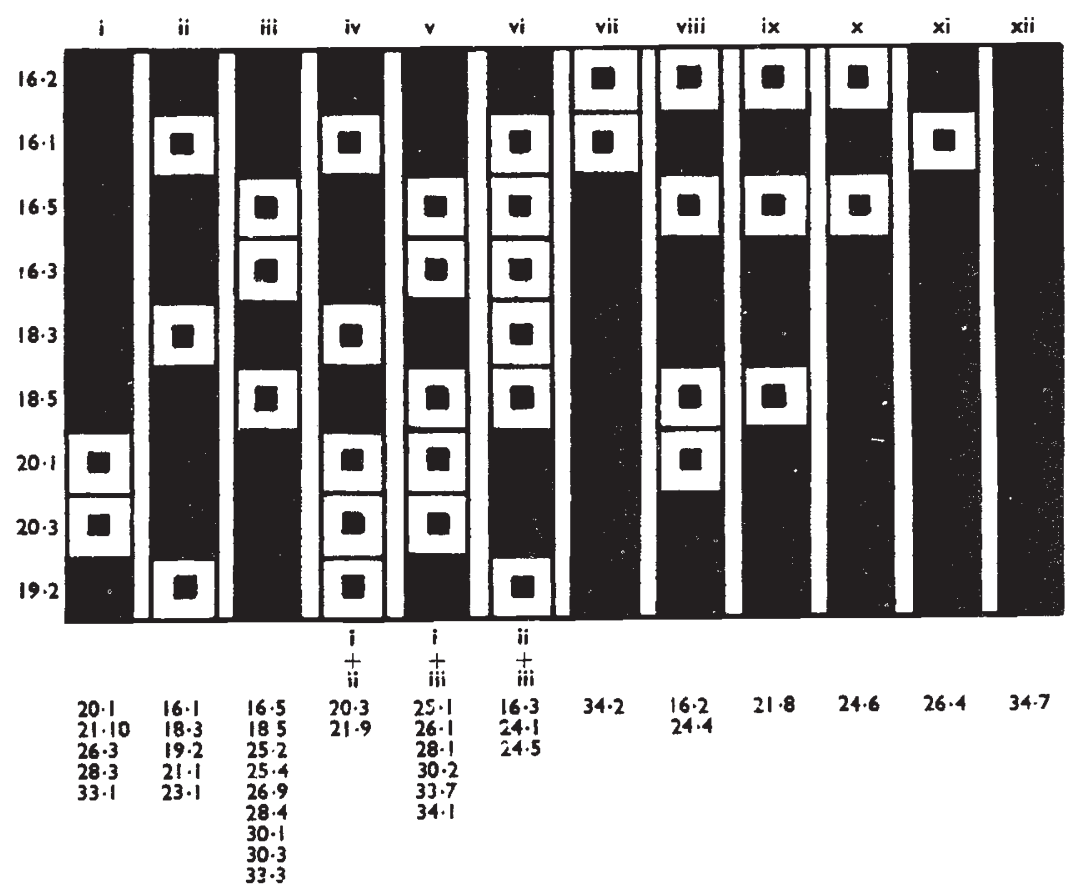

Frc. 5. - Thirty-eight inter-family test plants used as $\sigma^{t} \sigma^{t}$ are grouped according to their twelve different reactions with 9 test plants used as of?. $\mathcal{N} . B$. The incompatibilities of groups (iv), (v) and (vi) are the sums of the compatibilities of groups (i), (ii) and (iii) in pairs.

3 and 4 because as they are the two alleles in plant 14.I they will always occur as alternate alleles in any family of which it is a parent. We can therefore arbitrarily attribute the genotype 2.3 to (iv) and I.3 to (vi). By an extension of this argument (i) has 2 active in the pollen; (ii) has 3 active and (iii) has $I$ active. (It will be noted that we have obtained this information without reference to the genotypes of the nine tester plants used as females.)

From this starting point we are able to make an almost complete analysis of the whole of the data in the inter-family crosses. Thus, in the family 19-20 we expect the genotypes $2.3,2.4,3.8$ and 4.8 . We know that 20.1 has 2 active in the pollen, 19.2 has 3 active and 20.3 is 2.3. Therefore 20.1 must be $2.4,19.2$ must be 3.8 and the 
self-fertile plants will be the fourth genotype 4.8. Having determined the genotype of all our test plants in this way we can establish which alleles are active in which combinations. The data from the twentytwo tester plants intercrossed in all ways is shown in fig. 6 . The plants have been arranged according to their behaviour, and the conclusions as to the behaviour of the S-alleles in pollen and style are shown at the bottom of the columns and the left of the rows. Sometimes an allele is in an intermediate condition, not acting at

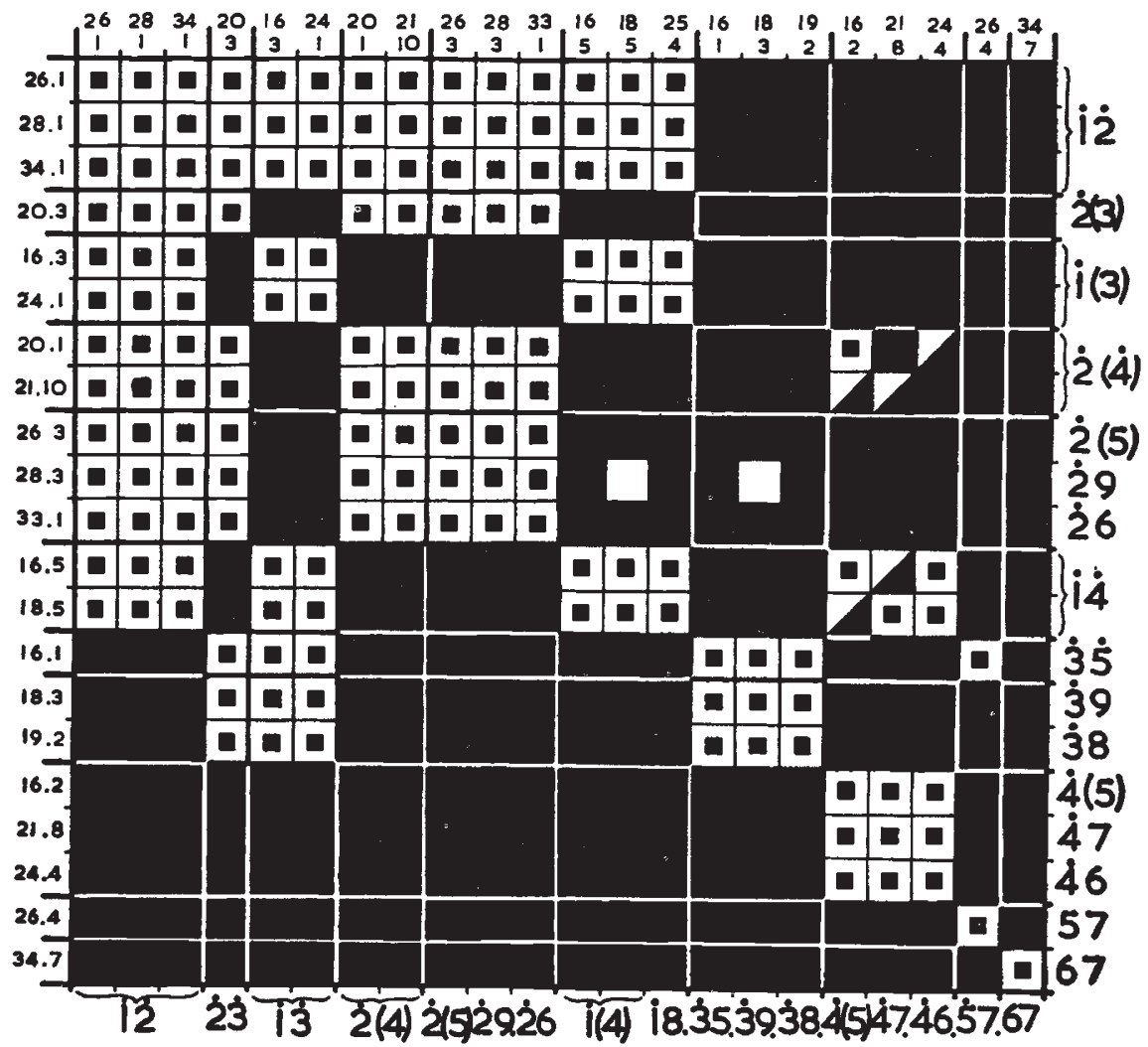

Fig. 6. -The 22 inter-family test plants intercrossed in all possible ways (except 25.4 which was not used as a o) and grouped according to their behaviour. At the end of the row or column is given the genotype and gene activities inferred from the results. In addition to those symbols used in fig. $2,(\dot{4})$ indicates weak activity.

sufficient strength to cause full incompatibility. It is then shown thus : (4). Where the information is insufficient the symbol is unqualified. (c) Method of inference.-Extreme caution must be used in interpreting the data since the activity of the alleles in style and pollen may be quite independent. Having found an adequate explanation of the data one is tempted to cease searching for alternatives. But we are here trying to obtain definite information about the interaction of alleles and therefore we must allow for all types of gene action not excluded by the data. 
If we confine our attention to the intra-family pollinations which have disclosed four classes, it is usually possible to arrange the $4 \times 4$ pattern of compatibilities so that whereas the top left to bottom right diagonal (representing the intra-class pollinations) is fully incompatible, the other diagonal is fully compatible. This is because in families containing four alleles it is always possible to group the four classes into two pairs which have no common allele and are thus inevitably cross compatible. The fully compatible diagonal is obtained when the two innermost and two outermost pairs of classes are without a common allele. Thus :

Conversely, if a 4-group, 4-allele family is arranged so as to give a compatible diagonal, it is probable that the inner and outer pairs

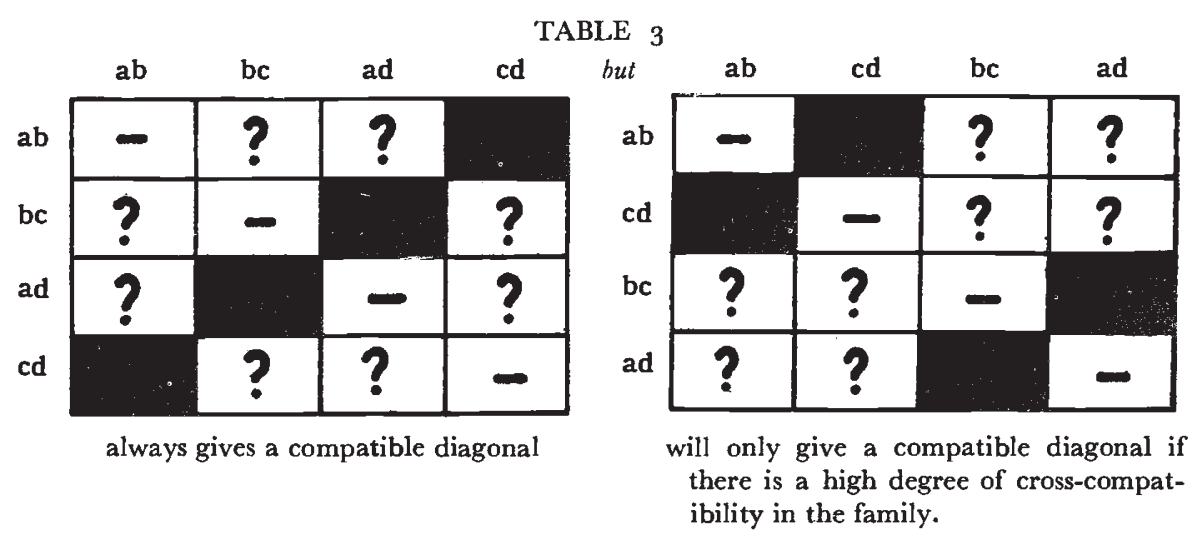

of groups are complementary, unless the degree of cross-compatibility between groups is high. An incorrect diagnosis will probably be recognised during later cross-testing.

An important exception to the rule of the compatible diagonal arises when the parents had one allele in common so that the four genotypes in the family are produced by only three alleles. One of the classes may then be incompatible with the other three classes. On the other hand, if it is compatible with one of the other classes, it will be possible to produce a compatible diagonal, but further analysis on the assumption that one is dealing with a four-allele family instead of in fact a three-allele one will be misleading. That is obviously one trap to beware of in such analyses. Further data in the form of inter-family tests or backcrosses should reveal the true situation.

Having determined which pairs of genotypes have no common allele one can arbitrarily designate the alleles a b c and d and examination of the eight interclass pollinations not on the diagonals will give information of their activities. All eight pollinations are between classes with one common allele. If any are incompatible then the common allele must be active in both the style of one and the pollen of the other. If any such crosses are compatible one can reach a 
definite conclusion only if the common allele has already been shown to be active in one of the classes. It must then be inactive in the other. If one allele has shown itself inactive in either style or pollen, the other allele must be active in both style and pollen of every selfincompatible genotype. But if two classes with a common allele of hitherto unknown activity are compatible, the allele may be inactive in style of one, pollen of the other, or both.

Let us now make such an analysis on family $21-2$ whose interclass compatibilities are shown in fig. 7, arranged so as to give a compatible diagonal. For the argument to be followed more easily it is reproduced here.

TABLE 4

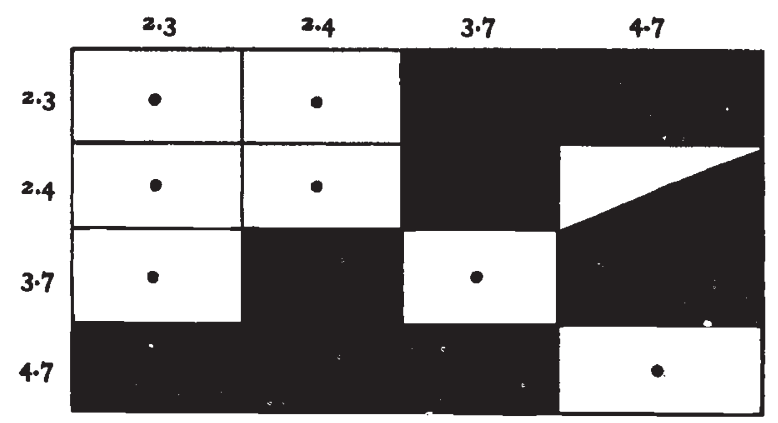

Excluding the diagonals, examination of the incompatible pollinations enables us to conclude that 2 is active in both style and pollen of 2.3 and 2.4 and that 3 is active in style of 3.7 and pollen of 2.3.

The partial incompatibility of pollination $2.4 \times 4.7$ needs special consideration. In detail, a $\dot{2} .4$ plant, pollinated by six 4.7 plants gave full compatibility with three but only partial compatibility with the other three. Thus 4 either in style of $\dot{2} .4$ or pollen of 4.7 or in both is not acting at full strength but we know nothing more definite.

Our conclusions so far are summarised as follows :

$\begin{array}{lllllll}\text { Pollen } & . & . & \dot{2} .3 & \dot{2} .4 & 3.7 & 4.7 \\ \text { Style } & . & . & \dot{2} .3 & \dot{2} .4 & \dot{3} .7 & 4.7\end{array}$

Let us now turn to the compatible pollinations.

All that we are able to conclude from the compatible pollinations $\dot{2} .3 \times 3.7,4.7 \times \dot{2} .4,4.7 \times 3.7$ and $\dot{3} .7 \times \mathbf{4} .7$ is that 3 is inactive in style of $\dot{2} .3$, pollen of 3.7 , or both; 4 is inactive in the style of 4.7 , pollen of $\dot{2.4}$, or both ; 7 is inactive in style of 4.7 , pollen of 3.7 , or both, and also inactive in style of $\mathbf{3} \cdot 7$, pollen of $\mathbf{4} \cdot \mathbf{3}$, or both.

We can however go a stage further because, since 4.7 is self-sterile, 4 and 7 cannot both be inactive in the style.

So we have made a little progress. But we can still draw on information from the inter-family pollinations of fig. 6 , which show 


\section{6-7}
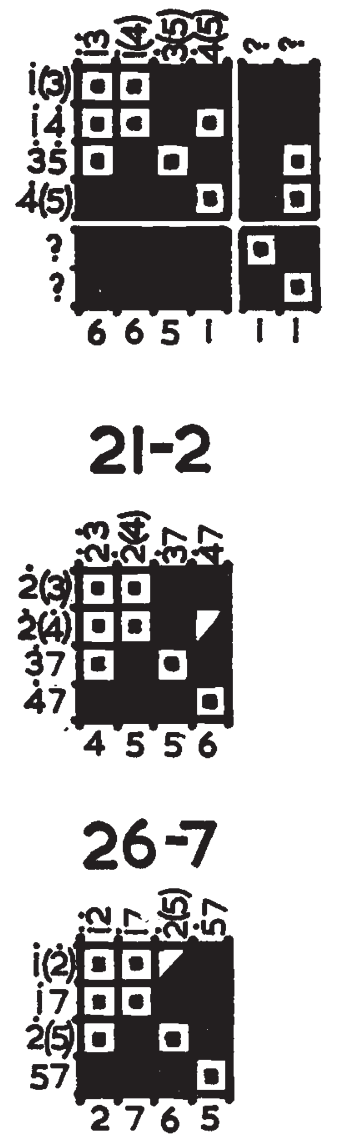

18

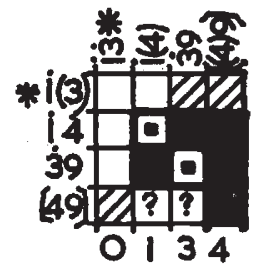

\section{$19-20$}

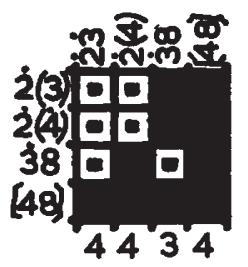

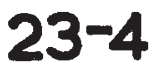
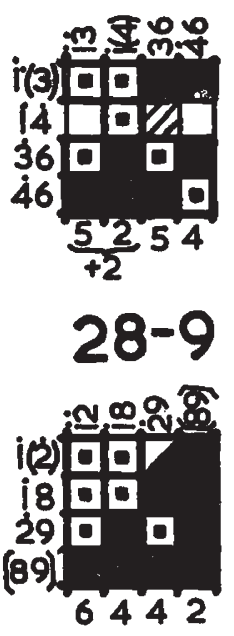

\section{5}
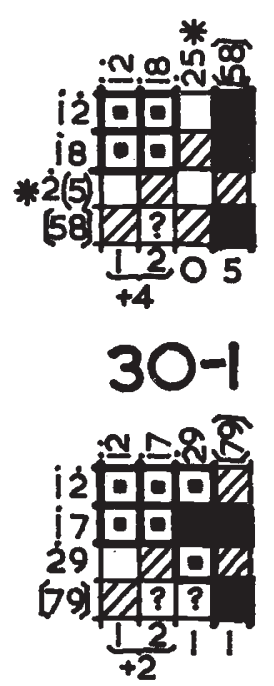
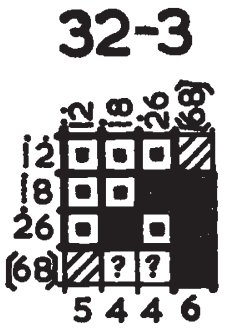

34-5

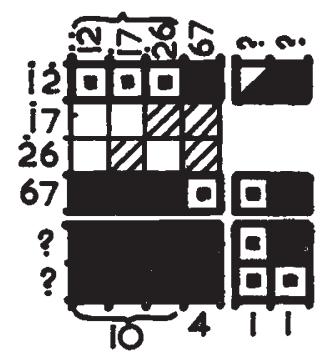

FIG. 7.-A summary of all class compatibilities within families, giving their genotypes, activities and frequencies (at foot of columns). In addition to the symbols of figs. 4 and 6 are the following :

[58] self-fertile ;

$\square$ pollination not made but presumed incompatible ;

- pollinati n not made, but presumed compatible ;

| | pollination not made, compatibility not predicted ;

* genotype expected but absent. 
us that 4 is active in pollen and style of $\dot{4.7}$. We are at once able to conclude that

(a) 4 in style of $\dot{2} \cdot(\dot{4})$ is almost inactive

(b) 4 in pollen of 2 . (4) is inactive.

From the same source we find that 3 is inactive in the style of $\dot{\boldsymbol{2}}$.(3). Our whole knowledge of this family can now be summarised thus :

$\begin{array}{lllllll}\text { Pollen . } & . & . & \dot{2} \cdot \dot{3} & \dot{2} .(4) & 3.7 & \dot{4} \cdot 7 \\ \text { Style . } & . & . & \dot{2} \cdot(3) & \dot{2} .(\dot{4}) & \dot{3} \cdot 7 & \dot{4} \cdot 7\end{array}$

To this we may add that some of the remaining alleles must be inactive. Not all can be, for since 37 is self-sterile, either 3 or 7 must be active in both pollen and style.

The interpretations of all intra-family results of fig. 4 , based on similar analyses, are given in fig. 7. Self-fertile genotypes are placed entirely in parenthesis, but this must not be taken to imply that both alleles are necessarily inactive in the pollen and style.

(d) Second generation.-Further evidence was obtained from a second generation raised from all compatible crosses within family 19-20. These were :

TABLE 5

\begin{tabular}{|c|c|c|c|c|c|c|c|c|c|c|c|}
\hline Cross & Family & Parental & \multicolumn{9}{|c|}{ Expected progeny genotypes } \\
\hline $\begin{array}{c}19^{1} \times 19^{4} \\
19^{4} \mathrm{~s}, \\
20^{2} \times 19^{1} \\
20^{2} \times 19^{4} \\
20^{5} \times 19^{4} \\
20^{5} \times 19^{1}\end{array}$ & $\begin{array}{l}36 \\
37 \\
3^{8} \\
39 \\
4^{0} \\
4^{1}\end{array}$ & $\begin{array}{c}3.8 \times 4.8 \\
4.8 \\
2.4 \times 3.8 \\
2.4 \times 4.8 \\
2.3 \times 4.8 \\
2.3 \times 3.8\end{array}$ & $\begin{array}{l}3.4 \\
3.4 \\
3.4\end{array}$ & $\begin{array}{l}3.8 \\
\\
3.8 \\
3.8\end{array}$ & $\begin{array}{l}4.8 \\
4.8 \\
4.8 \\
4.8\end{array}$ & $\begin{array}{l}8.8 \\
8.8\end{array}$ & $\begin{array}{l}4.4 \\
4.4\end{array}$ & $\begin{array}{l}2.3 \\
2.3\end{array}$ & $\begin{array}{l}2.8 \\
2.8 \\
2.8 \\
2.8\end{array}$ & $\begin{array}{l}2.4 \\
2.4\end{array}$ & $3 \cdot 3$ \\
\hline
\end{tabular}

In addition, as a control, a re-sowing was made of family $2 \mathrm{I}$, which also served as a check on the peculiar reciprocal differences in behaviour of 3 and 4 .

Fig. 8 shows the results obtained in the intra-family pollinations, together with expectations based on the previous generation. In general, agreement is very good. Of special importance is family 37 produced by selfing the self-fertile genotype 4.8 which segregates a single self-sterile group as a recessive. This is 4.4 , showing 8 to be a self-fertility allele at the S-locus.

New evidence is obtained on the genotype 3.4. The inability to distinguish 3.4 from 3.8 in families 36 and 40 shows that 3 must be active in pollen and style though the occasional half-compatibility of some pollinations indicates a possible weakening of 3 , probably in the style. The activity of 4 in 3.4 was tested by special crosses using 4.4 plants from family 37 and 3.4 plants from family 38 the only one in which this genotype could not be confused with 3.8. The crosses were compatible on to 4.4 styles but only partially compatible on to 3.4 styles. Here 4 is recessive to 3 in pollen but only partially so in style.

The activity of 4 was also tested in self-fertile 4.8 plants from family 


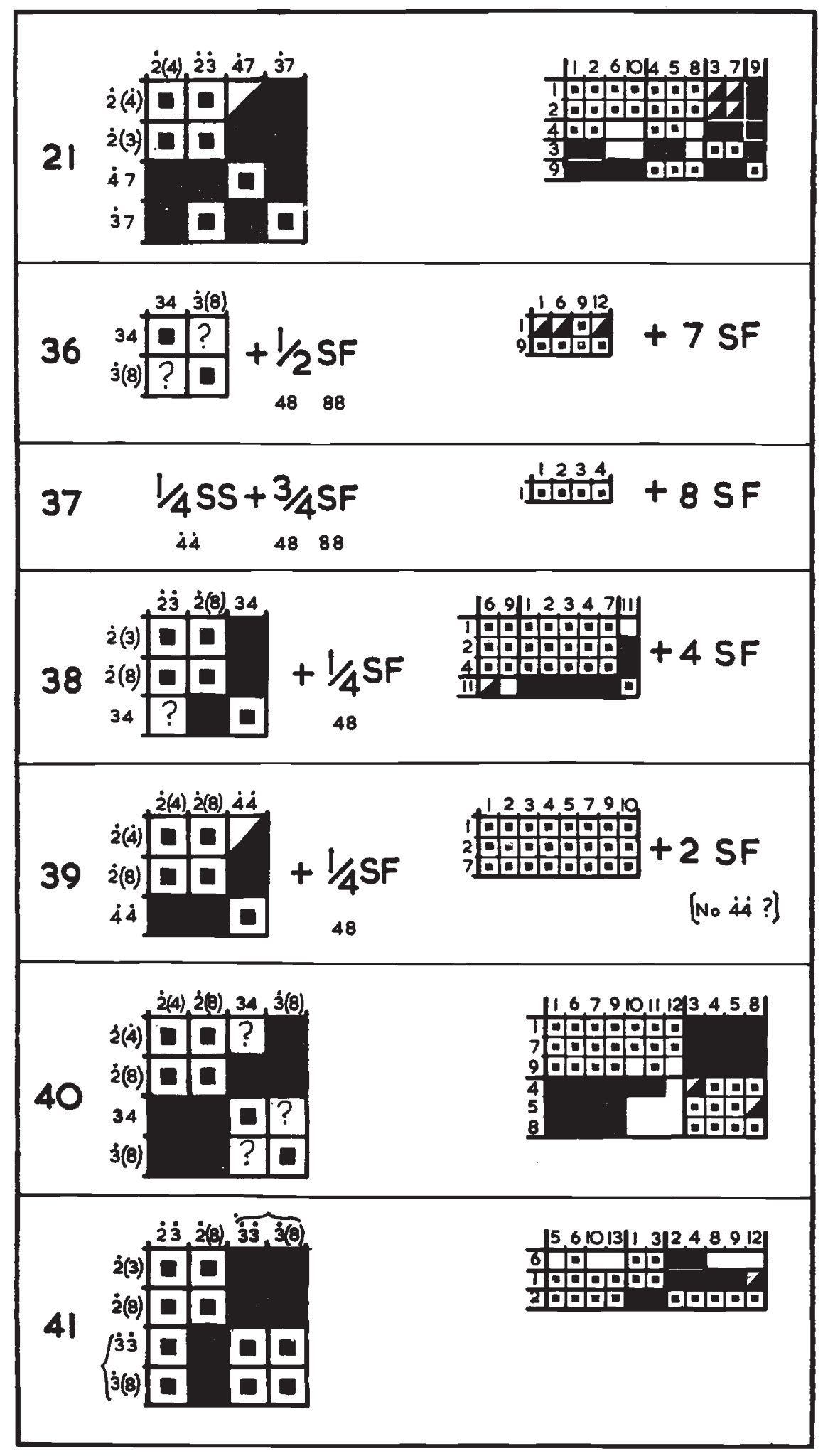

Fic. 8.-The expected genotypes and their reactions in the second generation (left) compared with the actual results (right). 
39 using 4.4 plants as testers. This showed 4 to be fully active in style but inactive in pollen. Thus self-fertility does not exclude the unilateral activity of S-alleles.

(e) Gene interactions.--The evidence for gene interactions in the various heterozygotes varies greatly in extent. The weight of the evidence for all those genotypes in which something is known of both alleles is shown in table 6 .

TABLE 6

The number of pollinations showing full activity, weakness or recessivity of the two alleles in those heterozygotes in which the behaviour of both alleles is known

\begin{tabular}{|c|c|c|c|c|c|c|c|}
\hline \multirow{2}{*}{ Genotype } & \multirow{2}{*}{ Allele } & \multicolumn{3}{|c|}{ Style } & \multicolumn{3}{|c|}{ Pollen } \\
\hline & & $\begin{array}{l}\text { Fully } \\
\text { active }\end{array}$ & Weak & Recessive & $\begin{array}{l}\text { Fully } \\
\text { active }\end{array}$ & Weak & Recessive \\
\hline 1.2 & I & $\begin{array}{l}39 \\
37\end{array}$ & $\cdots$ & $\begin{array}{l}\ldots \\
\ldots\end{array}$ & $\begin{array}{l}3^{8} \\
3^{1}\end{array}$ & $\begin{array}{l}\ldots \\
\ldots\end{array}$ & $\begin{array}{l}\ldots \\
\ldots\end{array}$ \\
\hline 1.3 & $\begin{array}{l}1 \\
3\end{array}$ & $\begin{array}{l}35 \\
\ldots\end{array}$ & $\begin{array}{l}\ldots \\
\ldots\end{array}$ & $\begin{array}{l}\ldots \\
3^{1}\end{array}$ & $\begin{array}{l}18 \\
20\end{array}$ & $\begin{array}{l}\ldots \\
\ldots\end{array}$ & $\begin{array}{l}\ldots \\
\ldots\end{array}$ \\
\hline 2.3 & $\begin{array}{l}2 \\
3\end{array}$ & $\begin{array}{l}24 \\
\ldots\end{array}$ & $\begin{array}{l}\ldots \\
\ldots\end{array}$ & 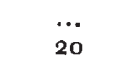 & $\begin{array}{l}27 \\
21\end{array}$ & $\begin{array}{l}\ldots \\
\ldots\end{array}$ & $\begin{array}{l}\ldots \\
\ldots\end{array}$ \\
\hline I. 4 & $\begin{array}{l}I \\
4\end{array}$ & $\begin{array}{r}38 \\
6\end{array}$ & $\underset{2}{2}$ & I. & $\begin{array}{l}22 \\
\ldots\end{array}$ & $\begin{array}{l}\ldots \\
\ldots\end{array}$ & $\dddot{18}$ \\
\hline 2.4 & $\begin{array}{l}2 \\
4\end{array}$ & $\begin{array}{r}32 \\
1\end{array}$ & $\begin{array}{l}\ldots \\
\text { I0 }\end{array}$ & $\dddot{6}$ & $\begin{array}{l}25 \\
\ldots\end{array}$ & $\begin{array}{l}\ldots \\
\ldots\end{array}$ & $\dddot{\ldots 8}$ \\
\hline 3.4 & $\begin{array}{l}3 \\
4\end{array}$ & * & $\begin{array}{l}1 \\
3\end{array}$ & $\begin{array}{l}\ldots \\
\cdots\end{array}$ & $\begin{array}{c}* \\
\ldots\end{array}$ & $\begin{array}{l}\ldots \\
\ldots\end{array}$ & $\begin{array}{r}\cdots \\
3\end{array}$ \\
\hline 2.5 & $\begin{array}{l}2 \\
5\end{array}$ & $\begin{array}{l}10 \\
\cdots\end{array}$ & $\begin{array}{l}\ldots \\
\cdots\end{array}$ & ${ }_{4}+$ & $\begin{array}{c}8 \\
\cdots\end{array}$ & $\begin{array}{l}\ldots \\
\cdots\end{array}$ & it \\
\hline 3.5 & $\begin{array}{l}3 \\
5\end{array}$ & $\begin{array}{l}15 \\
1 \dagger\end{array}$ & $\ldots$ & $\begin{array}{l}\ldots \\
\ldots\end{array}$ & $\begin{array}{l}2 \\
?\end{array}$ & $\dddot{p}$ & $\dddot{p}$ \\
\hline 4.5 & $\begin{array}{l}4 \\
5\end{array}$ & $\begin{array}{c}4 \\
\cdots\end{array}$ & $\begin{array}{l}\ldots \\
\cdots\end{array}$ & it & $\begin{array}{c}6 \\
\ldots\end{array}$ & $\begin{array}{l}\ldots \\
\cdots\end{array}$ & it \\
\hline 4.f & 4 & 3 & $\ldots$ & $\ldots$ & $\cdots$ & $\ldots$ & 4 \\
\hline
\end{tabular}

I.f, 2.f, 3.f. Recessivity of $f$ on both sides is proved by the self-sterility of these genotypes.

* Failure to distinguish 3.4 from 3.8 in families containing both, indicates activity of 3 with possibly some weakening.

$\dagger$ All evidence with this sign traces back to a single pollination $5.6 \times 3.5$ which was incompatible. Therefore little weight can be attached to it.

Out of a total of 45 possible combinations only 6 homozygotes and 4 heterozygotes are entirely unknown. Of a large number all we know is that one of the alleles is active. Only 19 phenotypes are thoroughly analysed.* Of these, 13 are alike in pollen and style (four being homozygotes without the possibility of interaction) and the remainder are more or less dissimilar.

* Note the paradox that since the phenotype is so complex it is easier to determine a plant's genotype than its phenotype. 
The most striking features are the contradictory dominance relations of 3 and 4 . Allele 3 is active in the pollen of genotypes I.3 and 2.3 but recessive to $I$ and 2 in the style. On the other hand 4 is active in the style of genotypes I.4 and 2.4, though not always strong enough to give complete incompatibility, and recessive to I and 2 in the pollen. These genotypes have been studied from a large number of pollinations so that there can be no doubt of the validity of these assertions. Particular interest therefore attaches to the activity of the alleles in 3.4 plants. The evidence of the second generation shows that 3 is active in pollen and style, whereas 4 is active only in the style and then imperfectly. Since 4 is active in styles of 1.4 and 2.4 while 3 is recessive to I and 2 one might have expected 4 to be dominant over 3 in style of 3.4 making that genotype self-fertile. This is not so.

(f) Self-fertility.-It will be noticed that evidence is most easily obtained about those alleles which are frequently active. Where alleles are usually recessive there are no pollinations available to prove their activity in any combination where they might be active except by producing them in the homozygous condition. This applies in particular to the self-fertile genotypes. In two of the families, I 9-20 and 28-29, the self-fertiles were tested in all combinations against their sibs but they gave no information about the activity of the alleles in pollen or style because the alleles concerned were recessive or partially recessive in the self-sterile sibs. This was rectified in family $19-20$ by studying the second generation. Over all the selffertile genotypes the only definite conclusions are about 4.8, described above, and 4.9 in family I 8 where, since $\dot{i}, \dot{4} \times 4.9$ is compatible, 4 must be inactive in the pollen. It may be pointed out that inactivity of both alleles in style or pollen or reversed dominance (e.g. (4). $\dot{9}$ in pollen and $\dot{4}$.(9) in style) would be sufficient to produce full selffertility. There is no evidence so far that would rule out reversed dominance since there is a certain independence of gene action in pollen and style. Genotype 3.4 though self-sterile comes very close to being self-fertile through reversed dominance. Self-fertility due to homozygosity for a recessive self-fertility allele is ruled out in the case of 4.8. But 5 is known to be active in some genotypes and 6.7 is self-sterile, proving that either 6 or 7 or both are not self-fertility alleles. Thus, of the five self-fertile genotypes, 4.8, 4.9, 5.8, 6.8, 7.9 and 8.9, only two, 8.9 and 6.8 or 7.9, could be homozygous for a selffertility allele.

This has a bearing on the number of S-alleles in this material, of which the maximum number was 9. We know that all the alleles shown to be active (I, 2, 3, 4 and 5) are different. The above evidence of the self-fertiles shows that 8,9 and 6 or 7 could be the same selffertile S-allele. But whilst 4.8, 4.9, 5.8, 6.8 and 7.9 are self-fertile 4.6, 4.7, 5.7 and 6.7 are self-sterile. Thus neither 6 nor 7 can be identical with 8 or 9 , but 8 and 9 are probably identical self-fertility alleles. 
We may rename them $f$. The simplest explanation therefore is that 8 and 9 are the same self-fertility allele (f) which is dominant to 4 , 5 and $6(=7$ ?) and recessive to $I, 2$ and 3 in the pollen, but recessive to at least $1,2,3$ and 4 in the style and possibly to 5, 6 (and 7) as well. Thus the number of alleles in this material, originating from six plants, is 7 or 8 . Their dominance relations are summarised in fig. 9 . The connecting lines between alleles denote what is actually known about their relationships. Though 6 and 7 are unconnected with the other alleles we know they must be low in the dominance series because they are recessive in either style or pollen, or both, to all the others with the exception of 5 whose relation with it is not known. They are therefore placed at the bottom.

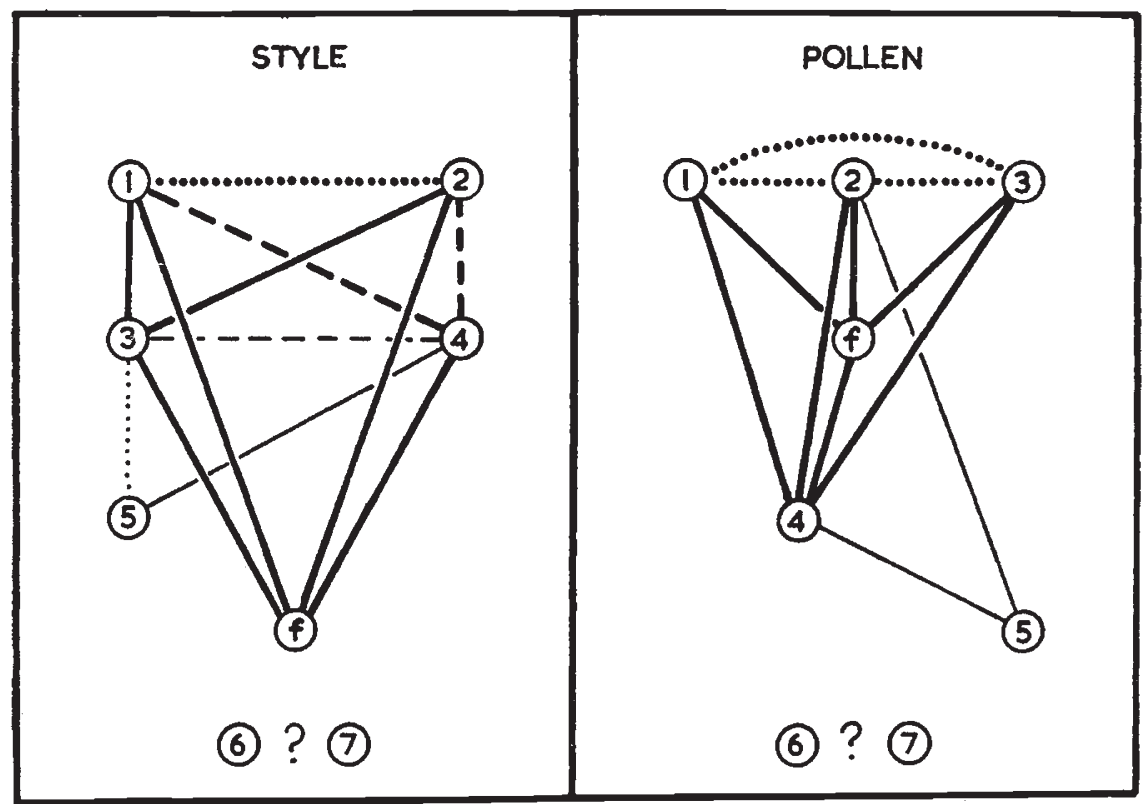

Fig. 9.-The S-alleles arranged spatially in accordance with their dominance relations.

Entire lines : dominance of upper allele over lower.

Broken lines : incomplete dominance of upper over lower.

(In the case of alleles 3 and 4 in the style, both alleles are slightly weakened.)

Dotted lines : independence of alleles (no dominance).

Thinner lines and smaller dots : evidence meagre.

Alleles 6 and 7 : These are placed at the bottom with a query because their activity was not proven in any genotype but they are not self-fertility alleles. They are presumed to be low in the dominance series.

\section{DISCUSSION}

In view of the rather novel interactions revealed between the S-alleles it is important to establish confidence in the experimental technique.

One hundred and fifty self-sterile plants were tested in 593 intrafamily pollinations involving five or six flowers each, and many repeated. Only four plants did not fall into expected groups. One 
of these was probably a male-sterile self-fertile as previously experienced. The other three could only be explained by contamination.

In the inter-family tests twenty-one plants were tested as females against a maximum of thirty-eight and a minimum of twenty-two plants, involving 605 pollinations (many repeated). No inexplicable results were obtained.

Examination of fig. 9 shows an overall similarity in the dominance relations in pollen and style but important differences in detail. In both, the alleles can be arranged in a linear order from top to bottom so that when dominance occurs it is usually of upper over lower. Independence of alleles may occur when they are at similar levels on this linear scale. Alleles which are independent in pollen can show dominance in sty ${ }^{1} e$ and vice versa.

The biggest difference between pollen and style is that the linear order of alleles $f$ and 4 is reversed though there are other quantitative changes especially of 3 relative to 4 without involving a reversal of the positions of the alleles.

When multiple allelic incompatibility with dominance was first discovered (Gerstel, I950; Hughes and Babcock, I950) there was an apparent contradiction. It might have been expected that the existence of a large number of mutually exclusive specific $\mathbf{S}$-alleles indicated multi-dimensional qualitative differences between them. A dominance series indicates a uni-dimensional quantitative difference. It was this contradiction which had led Lewis (1944) to conclude that such an incompatibility system did not exist. The present data throw some light on this contradiction. If we take the interactions in the pollen the alleles can be arranged in a linear order of dominance, and similarly, but not so consistently, in the style. But the two linear orders do not correspond. We can thus regard the overall relationship of the alleles as multi-dimensional, the dominance relationship representing the projection of these dimensions on to a line transept. We have only to assume the dominance in pollen and style to be represented by two unparallel lines through this multi-dimensional distribution to explain the change in dominance relationships. The shift of the dominance projection line from pollen to style would be due to the change of environment. If it were possible to measure the alleles in some other attribute in which they might vary, say rate of pollen tube growth, mutation rate, temperature at which destroyed and so on, the linear orders would be expected to vary more widely than does dominance between pollen and style.

\section{COMPARATIVE GENETICS}

It is desirable to compare the relationships of the alleles in Iberis with those in the few other known instances of sporophytic control of the pollen with multiple alleles.

In Cosmos (1954) Crowe has also found dominance and independence 
in pollen and style with incomplete correlation between the behaviour in the two sexes.

In both Crepis and Parthenium the authors imply that the S-alleles are independent in style and sometimes show dominance in the pollen. Their own data contradict this however, because the results can only be explained by assuming some dominance in the style also. (In Parthenium $\mathbf{R}_{\mathbf{4}}$ is recessive to $\mathbf{R I}, \mathbf{R}_{2}$ and $\mathbf{R}_{3}$. In Crepis $\mathbf{S}$ is recessive to $S_{2}, S_{3}$ and $S_{4}$. In any case each study of this phenomenon has involved only a small sample of alleles in each species. In my own experience my first study of Iberis showed almost complete correlation between dominance relations in the two sexes, the one exception

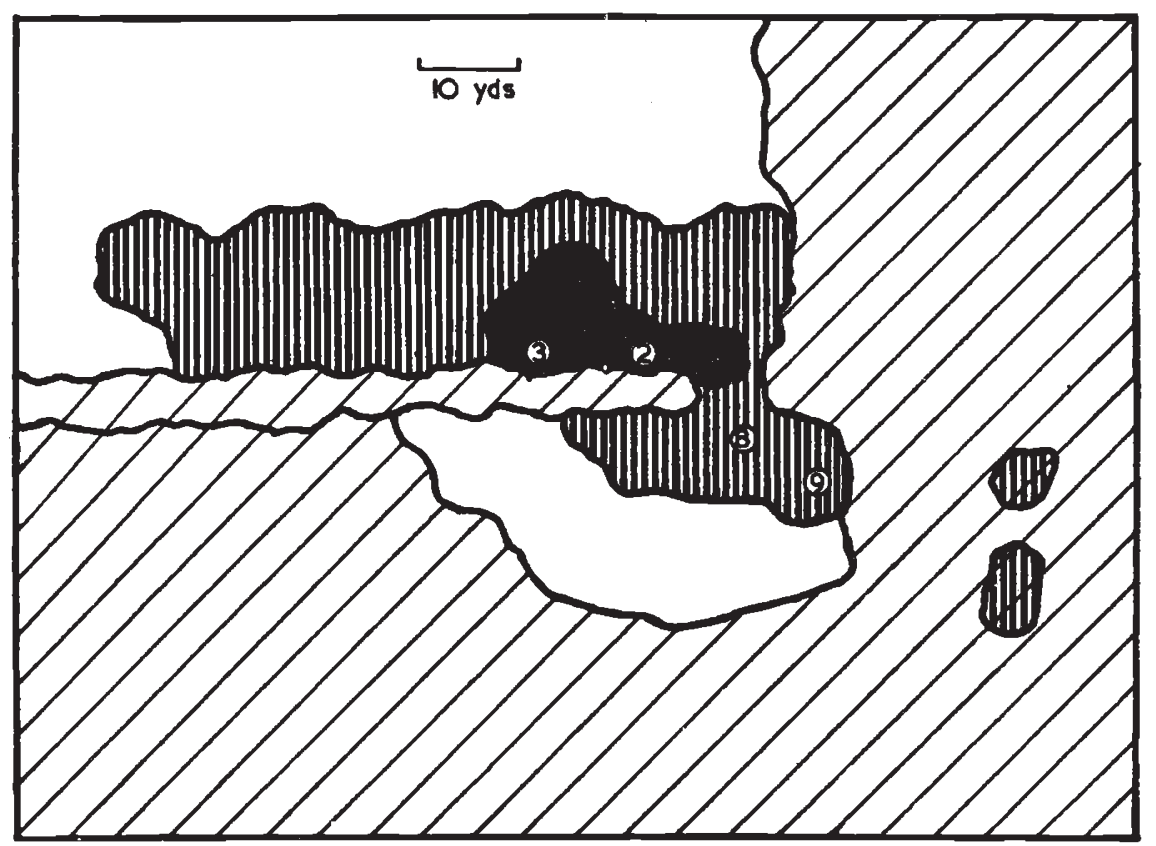

Fig. 10.-Map of the Royston Heath, Herts., population of Iberis amara. Black area : main concentration.

Vertical shading : remainder of population.

Diagonal shading : woodland and hedgerow.

Numbered circles : sites of analysed seed samples.

being based on slender evidence. It is obviously dangerous to generalise from small samples when sporophytic control in style and pollen presents so many possibilities for variation. There is probably no real contradiction between the results so far obtained from Parthenium, Crepis, Cosmos in the Compositae and Iberis in the Cruciferae even though from the presence of Iberis in a totally different family one might have anticipated important differences.

It would seem likely that the simultaneous existence of dominance and independence between S-alleles, in both style and pollen, is a necessary accompaniment of incompatibility systems which combine multiple alleles with sporophytic control of style and pollen. 


\section{CROSS-INCOMPATIBILITY IN A NATURAL POPULATION}

At the western margin of Royston Heath, Hertfordshire, there is a natural population of Iberis amara. According to Pryor's Flora of Hertfordshire there was in 1840 a population of this species "In and about a plantation adjoining west part of Royston Heath ". It appears that the same population has been in existence for over a century, for Pryor's description agrees with the present site. At the present time the population consists of thousands of individuals growing as annuals. It is reasonable to suppose therefore that an equilibrium has been achieved. Fig. Io represents a plan of the area.

Samples of seed were taken from three immediately neighbouring plants from each of eleven sites throughout the area. Seed from only four of these sites produced enough adult plants for these experiments.

Two suitable tester plants from each "family" * were used as females for testing the compatibility of pollen from different sources, within the same family, between families from the same site, and between sites. Each family is represented by the site number with the plant number of the seed parent as index.

The test pollinations were as follows (each cross represents two tester plants and as many pollen donors as are members of the family).

TABLE 7

\begin{tabular}{|c|c|c|}
\hline Within families & Within sites & Between sites \\
\cline { 1 - 2 } & & \\
\hline $2^{2}$ & $3^{2} \times 3^{1}$ & $2^{2} \times 3^{1}$ \\
$3^{1}$ & $3^{8} \times 3^{1}$ & $2^{2} \times 9^{2}$ \\
$3^{2}$ & $3^{8} \times 3^{2}$ & $3^{1} \times 9^{2}$ \\
$3^{8}$ & $8^{2} \times 8^{8}$ & $8^{8} \times 2^{2}$ \\
$8^{2}$ & $8^{8} \times 8^{2}$ & $8^{8} \times 3^{1}$ \\
$8^{8}$ & $9^{2} \times 9^{8}$ & $\cdots$ \\
$9^{8}$ & $9^{8} \times 9^{8}$ & $\cdots$ \\
& $\cdots$ & $\cdots$ \\
\hline
\end{tabular}

All pollinations were recorded as compatible or incompatible according to their stigma reaction but, as a check, the same crosses were scored later according to fruit setting. There were few cases of conflict between the two scorings. The general conclusions were the same with both scoring methods.

Out of $5^{2}$ plants grown, 5 were discarded as self-fertile.

Of the pollinations within families 27 out of 82 ( $3^{8}$ per cent.) were incompatible. In biparental families the average cross-incompatibility to be expected theoretically is 50 per cent. This is borne out by the earlier experiments of this paper. If we consider the two maternal alleles, one or other of which will be present in every plant even after open pollination, and assume that one of them is active

* By "family" is here meant the progeny of a single open-pollinated seed parent which will probably have several pollen parents. 
in all the progeny bearing it, cross-incompatibility due to the maternal alleles alone would be 25 per cent. If both alleles were active, but in only half the plants carrying them, the cross-incompatibility would be down to 12.5 per cent. At the other extreme, if all alleles were active the maternally derived cross-incompatibility would be 50 per cent. It is probable that 33 per cent. cross-incompatibility comprises an appreciable amount of cross-incompatibility between paternal alleles, either through a common pollen parent or through pollen parents with common alleles.

Out of $7 \mathrm{I}$ pollinations between families with a common site 8 (I I per cent.) were cross-incompatible, and out of 67 between sites only 3 ( $4 \cdot 8$ per cent.) were cross-incompatible.

The above figures are based on all pollinations. Since so much depends on whether one or both of the alleles of any tester plant are active, and on the identity of the active allele, a more exact comparison is made if we confine ourselves to pollinations made on to a common tester plant.

The first two rows have data selected from tester plants common to the columns being compared. Unfortunately very few test plants were common to "within sites" and "between sites". However, the results are the same for each row.

TABLE 8

\begin{tabular}{|c|c|c|c|c|c|c|}
\hline & \multicolumn{2}{|c|}{ I. Within families } & \multicolumn{2}{c|}{ 2. Within sites } & \multicolumn{2}{c|}{ 3. Between sites } \\
\cline { 2 - 3 } & $\begin{array}{r}\text { No. } \\
\text { pollinations }\end{array}$ & $\begin{array}{c}\text { Per cent. } \\
\text { incomp. }\end{array}$ & $\begin{array}{c}\text { No. } \\
\text { pollinations }\end{array}$ & $\begin{array}{c}\text { Per cent. } \\
\text { incomp. }\end{array}$ & $\begin{array}{c}\text { No. } \\
\text { pollinations }\end{array}$ & $\begin{array}{c}\text { Per cent. } \\
\text { incomp. }\end{array}$ \\
\cline { 2 - 6 } & 35 & 34 & 7 I & II & $\ldots$ & $\ldots$ \\
Comparison I-2 & 35 & 33 & $\ldots$ & $\ldots$ & 67 & 4.5 \\
Comparison I-3 & 30 & 33 & 7 I & II & 67 & 4.5 \\
All pollinations & 82 & 33 & \\
\hline
\end{tabular}

Now if all alleles have an even chance of being active (penetrance 50 per cent.) and all individuals are heterozygous, the frequency of random pairs of plants with a common S-allele will be four times the frequency of cross-incompatibility. Furthermore, according to the argument of an earlier paper (Bateman, 1947a), if the frequency of random pairs with a common allele is $n$ the total number of S-alleles is $4 \mathrm{n}$. If we apply these arguments to the data on cross-incompatibility between sites $(4.5$ per cent.) the proportion of random pairs with a common allele is 18 per cent. and the total number of S-alleles will be $4 / 0 \cdot 18=22$.

But we know that there is great variation in penetrance (even if the mean is 50 per cent.) according to the position of the allele in the dominance series. Furthermore we have evidence from the earlier experiments that independence is frequent, which would raise 
the mean penetrance above 50 per cent. Again we would expect on theoretical grounds considerable variation in gene frequency (Bateman, 1952) for the more recessive alleles would be more frequent than the more dominant ones. Allowance for any one of these sources of error would increase the estimated number of alleles. We can safely assume therefore that 22 is an under-estimate of the number of $\mathrm{S}$-alleles in this natural population of Iberis amara.

Further conclusions as to the structure of the population can be drawn from a comparison of the within-sites and between-sites pollinations. The greater cross-incompatibility within-sites demonstrates that even within a population extending about 30 yards in length (the distance between sites 9 and 3 ) there is no panmixis, but on the contrary a correlation between probability of inter-crossing (proximity) and relationships (as given by number of alleles in common).

It should be stated that the $\chi_{2}$ for heterogeneity between the within-sites and between-sites pollinations is only $2 \cdot 17$ for one degree of freedom. This is not quite significant at the 5 per cent. level ( $P=0.05-0 \cdot 10)$ even after allowing that we can halve the probability given in the table since we are only expecting deviation in one direction. But the data on which they are based are very consistent and the conclusions are in any case to be expected from the evidence on the behaviour of pollinating insects presented in an earlier paper (Bateman, 1947b).

\section{SUMMARY}

I. A study has been made of self-incompatibility in three samples of the Cruciferous species, Iberis amara.

2. Incompatible pollen fails to penetrate the stigma, but compatible pollen promotes a flushing of the stigma within 24 hours of pollination. This coloration has been used as the standard test of compatibility.

\section{Garden Races}

3. (a) The two samples demonstrated an incompatibility system (hitherto observed only in the Compositae) combining sporophytic control of both pollen and style with a multiple series of alleles.

(b) The two alleles of a heterozygote may act independently or one may be dominant over the other. With certain pairs of alleles, one of the pair is weakened though still active.

(c) Dominance and independence are found in both pollen and style. The relationship of a given pair of alleles need not however be the same in both.

(d) The alleles can be arranged in a linear order of dominance, independent alleles being at the same position. The same alleles form a partially different series in pollen and style.

(e) Self-fertility is fairly common. In the first sample it was due to a recessive gene independent of the $\mathbf{S}$ locus. In the second 
sample the self-fertility gene was a mutant at the $\mathbf{S}$ locus, and was recessive to some incompatibility alleles but dominant to others, at least in the pollen.

(f) Five parent plants from one of the samples shared six alleles. Six parents from the second sample shared seven or eight alleles.

\section{Wild Race}

4. (a) The degree of cross-incompatibility between unrelated plants indicated a large number of alleles, probably greater than 22.

(b) The cross-incompatibility between progenies of neighbouring plants approached that within progenies. Thus neighbouring plants are more closely related than a random sample from the population. I.e. there is no panmixis, even in a population extending over as little as 30 yards.

\section{REFERENCES}

BAKER, H. G. 1948. Dimorphism and monomorphism in the Plumbaginaceae. I. A survey of the family. Ann. Bot., N.S., 12, 207-219.

bateman, A. J. 1947a. Number of S-alleles in a population. Nature, $160,337$.

BATEMAN, A. J. 1947b. Contamination in seed crops. III. Relation with isolation distance. Heredity, $I$, 303-336.

BATEMAN, A. J. 1952. Self-incompatibility systems in angiosperms. I. Theory. Heredity, 6, 285-310.

CORRENS, c. 1913. Selbsterilität und Individualstoffe. Biol. Zent., 33, 389-423.

CROWE, L. 1954. Incompatibility in Cosmos bipinnatus. Heredity, 8, I-I I.

GERSTEL, D. U. I950. Self-incompatibility studies in Guayule. II. Inheritance. Genetics, 35, 482-506.

HUGHES, M. B., AND BABCOCK, E. B. 1950. Self-incompatibility in Crepis fotida $L$. subsp. rhoeadifolia. Genetics, 35, 570-588.

KAKIZAKI, х. 1930. Studies on the genetics and physiology of self- and crossincompatibility in the common cabbage. Jap. F. Bot., 5, 133-208.

LEWIS, D. 1944. Incompatibility in plants, its genetical and physiological synthesis. Nature, $153,575-578$.

LEWIs, D. 1947. Competition and dominance of incompatibility alleles in diploid pollen. Heredity, $1,85-108$.

RILEY, H. P. 1936. The genetics and physiology of self-sterility in the genus Capsella. Genetics, 21, 24-39.

SEARS, E. R. 1937. Cytological phenomena connected with self-sterility in the flowering plants. Genetics, 22, $130-181$.

stout, A. B. 1931. Pollen tube behaviour in Brassica pehinensis with reference to self-incompatibility in fertilisation. Amer. F. Bot., $18,686-695$. 